\title{
Central and peripheral actions of somatostatin on the growth hormone-IGF-I axis
}

\author{
Robert D. Murray, ${ }^{1}$ Kiwon Kim, ${ }^{1}$ Song-Guang Ren, ${ }^{1}$ Marjorie Chelly, ${ }^{2}$ \\ Yutaka Umehara, ${ }^{2}$ and Shlomo Melmed 1
}

\begin{abstract}
1Department of Medicine and 2Department of Surgery, Cedars Sinai Research Institute, UCLA School of Medicine, Los Angeles, California, USA.
\end{abstract}
\begin{abstract}
Somatostatin (SRIF) analogs provide safe and effective therapy for acromegaly. In a proportion of patients, however, SRIF analogs may lead to discordant growth hormone (GH) and IGF-I suppression, which suggests a more complex mechanism than attributable to inhibition of GH release alone. To elucidate whether SRIF acts peripherally on the GH-IGF-I axis, we showed that rat hepatocytes express somatostatin receptor subtypes-2 and -3 and that IGF-I mRNA and protein levels were suppressed in a dose-dependent manner by administration of octreotide. The inhibitory effect of SRIF was not apparent without added GH and in the presence of GH was specific for IGF-I induction and did not inhibit GH-induced c-myc or extracellular signal regulated kinase (ERK) phosphorylation. Pertussis toxin treatment of hepatocytes incubated with GH and SRIF, or with GH and octreotide, abrogated the inhibitory effect on GH-induced IGF-I, which confirms the requirement for the inhibitory G-protein. Treatment with SRIF and GH increased protein tyrosine phosphatase (PTP) activity and inhibited signal transducer and activator of transcription-5b (STAT5b) phosphorylation and nuclear localization. Octreotide also inhibited GH-stimulated IGF-I protein content of ex vivo-perfused rat livers. The results demonstrate that SRIF acts both centrally and peripherally to control the GH-IGF-I axis, providing a mechanistic explanation for SRIF analog action in treating patients with GH-secreting pituitary adenomas.
\end{abstract}

\section{Introduction}

The physiological and pharmacological actions of the widely distributed cyclopeptide somatostatin (SRIF) are almost exclusively inhibitory. SRIF has a broad range of actions that include inhibition of endocrine and exocrine gland secretion, gut motility, and cellular growth and proliferation $(1,2)$. The inherent pulsatility of pituitary growth hormone $(\mathrm{GH})$ release, which is important for biological activity (3), is governed by alternating episodes of stimulation by growth hormone releasing hormone (GHRH) and inhibition by SRIF released from the arcuate and periventricular nuclei of the hypothalamus respectively. GH, a protein secreted from the pituitary, acts both directly and indirectly via IGF-I induction to promote tissue growth and regulate metabolism. GH induces IGF-I secretion by the liver and peripheral target tissues, though hepatic-derived IGF-I accounts for most circulating IGF-I $(4,5)$. Current evidence suggests that IGF-I, secreted locally, is responsible for most GH dependent growth effects; however, it is likely that GH and IGF-I act in synergy on target tissues (6).

Acromegaly is a syndrome resulting from chronic excess $\mathrm{GH}$ secretion that usually results from a benign $\mathrm{GH}$-secreting pituitary adenoma (7). The resultant excess GH and IGF-I leads to classical somatic features characterized by organomegaly, cardiac dysfunction, insulin resistance, hypertension, arthropathy, colonic polyps, and premature mortality (7-12). Therapeutic modalities

Nonstandard abbreviations used: extracellular signal regulated kinase (ERK); growth hormone $(\mathrm{GH})$; growth hormone receptor (GHR); growth hormone releasing hormone $(\mathrm{GHRH})$; inhibitory G-protein $\left(\mathrm{G}_{\mathrm{i}}\right)$; janus kinase-2 (JAK2); protein tyrosine phosphatase (PTP); ribonuclease protection assay (RPA); signal transduction and activator of transcription (STAT); somatostatin (SRIF); somatostatin receptor subtype (SSTR); suppressor of cytokine signaling (SOCS).

Conflict of interest: $\mathrm{S}$. Melmed is a scientific consultant for, and receives research funding from, Novartis Pharma AG, Basel, Switzerland.

Citation for this article: J. Clin. Invest. 114:349-356 (2004). doi:10.1172/JCI200419933 for treating acromegaly include surgery $(13,14)$, radiotherapy $(15)$, and medical therapy (16-18). Since their introduction in the mid1980s, SRIF analogs have evolved as a mainstay of safe medical treatment following surgical failure, while patients await the effect of radiation, and are increasingly used for primary therapy of these tumors when indicated (19-21). Somatostatin analog administration effectively lowers circulating GH levels, normalizes IGF-I levels, and controls symptoms in most patients with acromegaly (19, 22-26). In some patients, GH suppression is discordant with persistent IGF-I elevation, and in others, clinical improvement may not necessarily correlate with biochemical control (27). There is compelling evidence that SRIF analogs act to suppress the GHIGF-I axis by inhibiting pituitary GH release $(28,29)$ and GHRH release from the hypothalamic arcuate nucleus (30). Whether SRIF analogs act on both pituitary and peripheral target tissues of $\mathrm{GH}$ to reduce GH-induced IGF-I production or symptoms of hypersomatotrophism has not been comprehensively studied.

Here we confirm the inhibitory action of SRIF and the SRIF analog octreotide on somatotroph GH release and further show that rat hepatocytes express both somatostatin receptor subtype-2 (SSTR2) and SSTR3, through which SRIF and octreotide dosedependently inhibit GH-induced IGF-I production. The inhibitory effects of SRIF on GH-induced hepatic pathways are specific for IGF-I induction and are also not observed in the absence of GH.

\section{Results}

Pituitary cultures. SRIF analogs inhibit GH secretion from cultured pituitary cells and pituitary adenoma cells in vitro, which suggests a direct in vivo action of SRIF analogs on the pituitary. Confirming this observation, both SRIF and octreotide $(10 \mathrm{nM})$ inhibited $\mathrm{GH}$ release from cultured rat pituicytes by $40 \% \pm 31 \%(P=0.012)$ and $42 \% \pm 31 \%(P=0.001)$, respectively; and from six GH-secreting pituitary adenomas by a mean of $29 \% \pm 15 \%(P=0.002)$ and $18 \% \pm 15 \%(P=0.38)$, respectively. SRIF and octreotide inhibited 
Table 1

Oligonucleotide primers

\begin{tabular}{|c|c|c|c|c|}
\hline & Primer & & $\begin{array}{l}\text { Annealing } \\
\text { temperature }\end{array}$ & $\begin{array}{l}\text { Expected } \\
\text { size }\end{array}$ \\
\hline \multirow[t]{2}{*}{$\beta$-Actin } & Sense & 5'-AGAGGGAAATCGTGCGTGAC-3' & $58^{\circ} \mathrm{C}$ & 158 bp \\
\hline & Anti & 5'-CAATAGTGATGATGACCTGGCCGT-3' & & \\
\hline \multirow[t]{2}{*}{ c-myc } & Sense & 5'-ACACCGAGGAAAACGACAAG-3' & $58^{\circ} \mathrm{C}$ & 412 bp \\
\hline & Anti & 5'-TATGGCTGAAGTCCCAAAGC-3' & & \\
\hline \multirow[t]{2}{*}{ GAPDH } & Sense & 5'-TGAAGGTCGGAGTCAACGGATTTGGT-3' & $58^{\circ} \mathrm{C}$ & 983 bp \\
\hline & Anti & 5'-CATGTGGGCCATGAGGTCCACCAC-3' & & \\
\hline \multirow[t]{2}{*}{ IGF-I } & Sense & 5'-CTGGTGGACGCTCTTCAGTT-3' & $58^{\circ} \mathrm{C}$ & 166 bp \\
\hline & Anti & 5'-TCAGCGGAGCACAGTACATC-3' & & \\
\hline \multirow[t]{2}{*}{ SSTR1 } & Sense & 5'-ATGTTCCCCAATGGCACC-3' & $58^{\circ} \mathrm{C}$ & $1115 b$ \\
\hline & Anti & 5'-CAGATTCTCAGGCTGGAAGTCCTC-3' & & \\
\hline \multirow[t]{2}{*}{ SSTR2 } & Sense & 5'-AGCAACGCGGTCCTCACGTT-3' & $58^{\circ} \mathrm{C}$ & 973 bp \\
\hline & Anti & 5'-GGAGGTCTCCATTGAGGAGG-3' & & \\
\hline \multirow[t]{2}{*}{ SSTR3 } & Sense & 5'-CTGCCTGTGGTTGTGTTCTC-3' & $58^{\circ} \mathrm{C}$ & $722 b$ \\
\hline & Anti & 5'-GCGACCACCAGGAAGTAGAG-3' & & \\
\hline \multirow[t]{2}{*}{ SSTR4 } & Sense & 5'-ATGGTAACTATCCAGTGCAT-3' & $58^{\circ} \mathrm{C}$ & 275 bp \\
\hline & Anti & 5'-GTGAGGCAGAAGACACTCGTGAAC & & \\
\hline \multirow[t]{2}{*}{ SSTR5 } & Sense & 5'-TGGTCACTGGTGGGCTCAGC-3' & $58^{\circ} \mathrm{C}$ & 1017 \\
\hline & Anti & 5'-CCTGCTGGTCTGCATGAGCC-3' & & \\
\hline
\end{tabular}

Application of each primer is described in the text.

GH release by more than $20 \%$ in five and three of the GH-secreting adenomas, respectively.

Hepatocyte SSTR subtype expression. A previous study, using ribonuclease protection assay (RPA), reported SSTR3 to be the only SRIF receptor subtype expressed in rat liver RNA extract (31). Before establishing whether SRIF could have a secondary peripheral site of action on the GH-IGF-I axis at the level of the hepatocyte, it was important to determine the presence of SSTR subtypes that could convey SRIF signal transduction. Isolated hepatocyte cDNA was subject to PCR with primers specific for the SSTR subtypes (Table 1). Both SSTR2 and SSTR3 were expressed by rat hepatocytes, while SSTR1, SSTR4, and SSTR5 expression was not detected. SSTR expression supports the hypothesis that SRIF has direct physiological effects on the hepatocyte.

IGF-I response to GH and SRIF in isolated hepatocytes. To establish the integrity of the isolated hepatocyte model with respect to induction of IGF-I by GH and to validate IGF-I quantitation by RPA, hepatocytes were incubated with $\mathrm{GH}(1-1,000 \mathrm{ng} / \mathrm{ml})$ for 24 hours. As expected, IGF-I mRNA measured by RPA showed a dose-dependent increase, with maximal induction by a GH dose of $500 \mathrm{ng} / \mathrm{ml}$ (Figure 1A). GH doses of 100 and $500 \mathrm{ng} / \mathrm{ml}$ led to 3.7- and 3.9fold induction of IGF-I mRNA at 24 hours, respectively $(P=0.03$ and $P=0.02$, respectively). Hepatocytes were incubated with $\mathrm{GH}$ $(500 \mathrm{ng} / \mathrm{ml})$ for up to 24 hours and in the absence of $\mathrm{GH}$ for 0 and 24 hours. GH induced IGF-I transcript only after 24 hours incubation, and in the absence of GH, IGF-I mRNA levels remained stable for the duration of the study (Figure 1B). Demonstration of SSTR

\section{Figure 1}

Cultured isolated rat hepatocytes incubated with (A) $\mathrm{GH}(1-1,000 \mathrm{ng} / \mathrm{ml})$ for 24 hours and (B) GH (500 ng/ml) or buffer for 0-24 hours. Cells were harvested for RNA and analyzed for IGF-I mRNA and $\beta$-actin by RPA. The IGF-I riboprobe corresponded to a 166-bp fragment of the mature IGF-I protein, and $\beta$-actin corresponded to a 125 -bp band. Upper and lower panels: representative blots; middle panel: mean fold IGF-I mRNA induction of 3 individual studies. ${ }^{\star} P<0.05$ compared with control. expression, stability of IGF-I transcript over the experimental period, and responsiveness to $\mathrm{GH}$ confirms that cultured isolated hepatocytes are a faithful in vivo model for studying effects of SRIF on GH-induced IGF-I production, independent of confounding factors such as hypothalamic input that occur in vivo.

Hepatocytes were next preincubated with $100 \mathrm{nM}$ SRIF14 or octreotide for one hour before stimulation with 100 or $500 \mathrm{ng} / \mathrm{ml} \mathrm{GH}$. Cells were incubated for 24 hours and IGF-I quantified by RPA. Both SRIF and octreotide inhibited GH-induced IGF-I transcription independent of the $\mathrm{GH}$ dose used to induce IGF-I (Figure 2A). These results suggest that SRIF and its analog suppress the GH-IGF-I axis by inhibiting pituitary $\mathrm{GH}$ release as well as GHinduced hepatocyte IGF-I production. To confirm whether changes in IGF-I mRNA that occur during GH and SRIF treatment of hepatocytes translate to changes in IGF-I protein, IGF-I content of medium derived from hepatocytes treated with $\mathrm{GH}$ $(500 \mathrm{ng} / \mathrm{ml})$ in the presence and absence of $100 \mathrm{nM}$ SRIF or octreotide was measured. GH increased IGF-I release from hepatocytes by $60 \%$ above basal levels at 24 hours $(P<0.0001$; Figure $3 \mathrm{~A})$. In the presence of SRIF and octreotide, GH-induced IGF-I increase was abrogated (32\% and $40 \%$ increase, respectively) (Figure 3A). Although GH-induced IGF-I remained significantly above baseline in the presence of octreotide $(P=0.01)$, in the presence of SRIF, GH-induced IGF-I increase was not different from baseline values. Therefore, SRIF inhibits both hepatic GH-induced IGF-I mRNA and protein secretion.

The specificity of the inhibitory effects of SRIF and octreotide on basal or GH-induced hepatic IGF-I transcription levels was tested. Hepatocytes were treated with $100 \mathrm{nM}$ SRIF or octreotide with no added GH, and IGF-I mRNA was analyzed by RPA. Basal IGF-I levels were readily measurable in the absence of added GH (Figure $2 \mathrm{~B}$, lane 1 ) and were unaffected by either SRIF or octreotide (Figure $2 \mathrm{~B}$, lanes $1-3)$. The inhibitory effect of SRIF and its analogs on hepatic IGF-I therefore appears to be dependent upon IGF-I induction by $\mathrm{GH}$, which indicates that the observed inhibition of GH-induced IGF-I likely results from interactions between SRIF and GH signaling pathways.
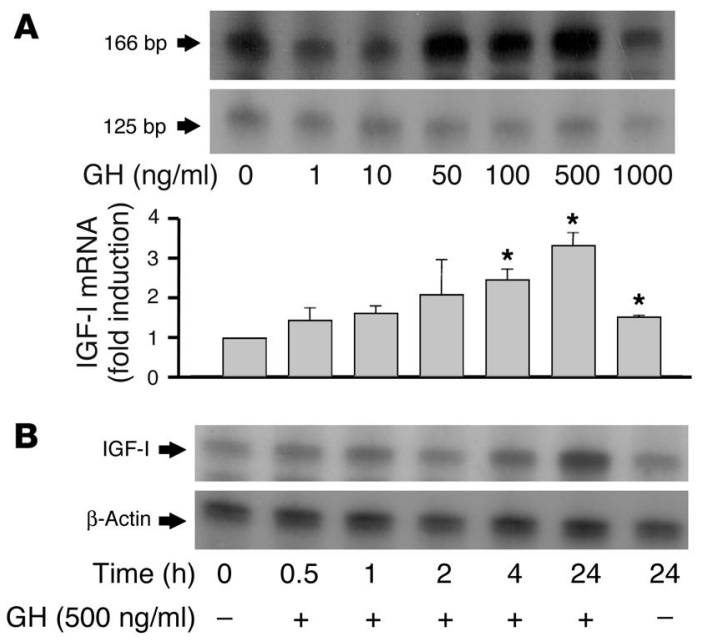
A

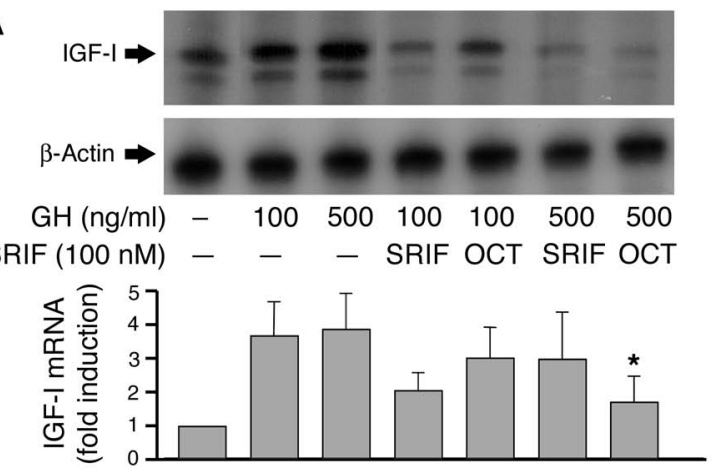

B
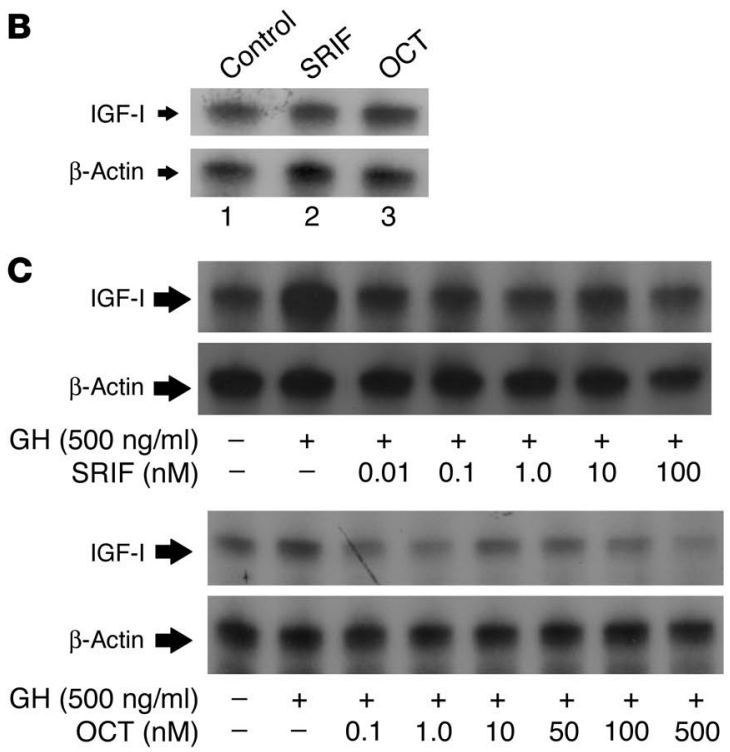

Effects of one-hour pretreatment with $10^{-11}$ to $10^{-7} \mathrm{M}$ SRIF on IGF-I mRNA induction by $500 \mathrm{ng} / \mathrm{ml} \mathrm{GH}$, as measured by RPA, showed that all doses of SRIF studied inhibited GH-induced IGF-I with no loss of SRIF effect at higher doses (Figure 2C, upper panels). A similar dose-dependent response to SRIF was observed when hepatocytes were incubated with $10^{-10}$ to $5 \times 10^{-7} \mathrm{M}$ octreotide (Figure 2C, lower panels). A previous study only of octreotide effects on GH-induced IGF-I in hepatocytes displayed a parabolic dose effect, with low octreotide doses inhibiting GH-induced IGF-I, whereas higher doses had no effect (32).

IGF-I response to GH and SRIF in perfused livers. To establish that the inhibitory effect of SRIF on GH-induced IGF-I in isolated hepatocytes was not a function of the in vitro model, we also studied the effect of octreotide on IGF-I content of perfused whole rat livers ex vivo. This model has the advantage over the isolated hepatocytes that the liver retains its normal cellular architecture. The disadvantage of this model lies in the fact that it is difficult to isolate the GH system from the effect of other hormones affecting IGF-I transcription rate immediately before surgery. Rat livers were perfused with buffer with or without GH in the presence and absence of octreotide for 60 minutes. GH was perfused as a $0.5 \mu \mathrm{g} /$ $\mathrm{ml}$ solution from minutes 15 to 25 and octreotide at $20 \mathrm{ng} / \mathrm{g}$ body weight/hour from minutes 0 to 60 . GH increased hepatocyte IGF-I protein content by $44 \%$ above livers perfused with buffer alone $(144 \% \pm 18 \%[n=5]$ vs. $100 \% \pm 8 \%[n=4] ; P=0.07$; Figure $3 \mathrm{~B})$. Co-perfusion of hepatocytes with GH and octreotide abrogated

\section{Figure 2}

SRIF suppresses $\mathrm{GH}$-induced hepatocyte IGF-I. (A) Isolated rat hepatocytes were incubated with GH (100 or $500 \mathrm{ng} / \mathrm{ml}$ ) for 24 hours with or without 1 hour preincubation with $100 \mathrm{nM}$ SRIF or octreotide (OCT). RNA was quantitated by RPA analysis. Upper panel: representative blot. Lower panel: mean fold induction of IGF-I mRNA of three individual experiments after normalization for $\beta$-actin. ${ }^{*} P<0.05 \mathrm{com}$ pared with GH-treated cells. (B) Representative RPA quantitation for IGF-I and $\beta$-actin content of isolated rat hepatocytes following incubation with $100 \mathrm{nM}$ SRIF or octreotide for 24 hours with no GH stimulation. Upper panel: IGF-I; lower panel: $\beta$-actin. (C) RPA analysis of IGF-I and $\beta$-actin from isolated rat hepatocytes treated with $\mathrm{GH}(500 \mathrm{ng} / \mathrm{ml})$ for 24 hours with and without preincubation with $0.01-100 \mathrm{nM}$ SRIF (upper two panels), or $0.1-500 \mathrm{nM}$ octreotide for 1 hour (lower two panels).

hepatocyte IGF-I protein content compared with livers perfused with GH alone $(76 \% \pm 15 \%[n=5]$ vs. $144 \% \pm 18 \%[n=4] ; P=0.017)$, but not when compared with rat livers perfused with buffer alone $(76 \% \pm 8 \%[n=5]$ vs. $100 \% \pm 8 \%[n=5] ; P=0.20$; Figure $3 \mathrm{~B})$. These results support the observations of the isolated hepatocyte model that SRIF inhibits GH-induced hepatocyte IGF-I production.

SRIF inbibits GH binding to the GH receptor. Radiolabeled GH was used to measure GH binding to hepatocytes. Total binding was approximately $4.4 \%$ of the total ${ }^{125} \mathrm{I}-\mathrm{GH}$ added, and specific binding was approximately $1.5 \%$. Cells were pretreated with $100 \mathrm{nM}$ SRIF or octreotide for 30 minutes before addition of radiolabeled GH and thereafter incubated for an additional 30 minutes before quantitation of GH binding. Pretreatment with SRIF or octreotide reduced specific ${ }^{125}$ I-GH hepatocyte binding by $68 \%$ and $81 \%$ respectively (Figure 4 ). Thus, in addition to effects on IGF-I transcription and secretion, both SRIF and octreotide inhibit hepatocyte GH binding.

SRIF inbibition of hepatocyte function is specific for IGF-I. The specificity of SRIF and octreotide inhibition of GH-induced hepatic IGF-I was elucidated. Independent of IGF-I induction, GH potentiates cellular growth and proliferation via MAPK. To determine if SRIF inhibited GH activation of MAPK in addition to IGF-I transcrip-
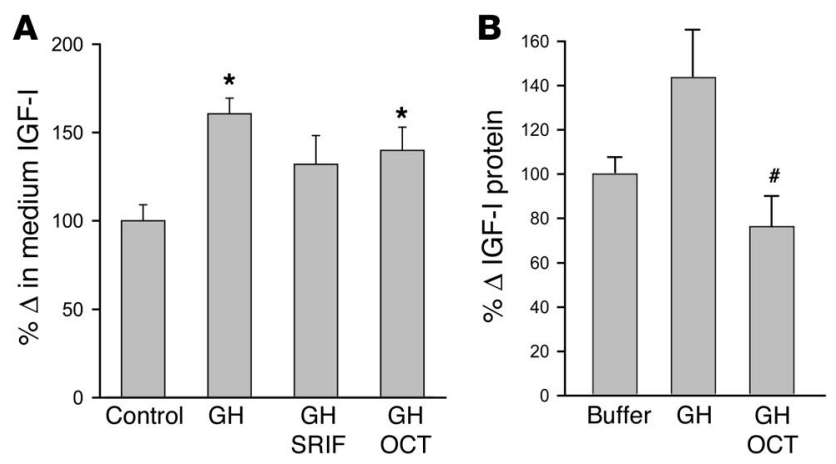

\section{Figure 3}

Octreotide suppresses hepatic IGF-I in vitro and in vivo. (A) Isolated rat hepatocytes incubated with vehicle or $\mathrm{GH}(500 \mathrm{ng} / \mathrm{ml})$ in the presence and absence of $100 \mathrm{nM}$ SRIF or octreotide. Medium was collected after 24 hours and assayed for IGF-I content by RIA after acid-alcohol extraction. (B) Rat livers perfused ex vivo with Krebs buffer with or without $0.5 \mu \mathrm{g} / \mathrm{ml} \mathrm{GH}$ in the presence or absence of octreotide (20 $\mathrm{ng} / \mathrm{g}$ body wt/h) for 60 minutes. GH was perfused from minutes $15-25$ and octreotide from minutes $0-60$. ${ }^{*} P<0.05$ compared with control; ${ }^{\#} P<0.05$ compared with $\mathrm{GH}$-perfused livers. 


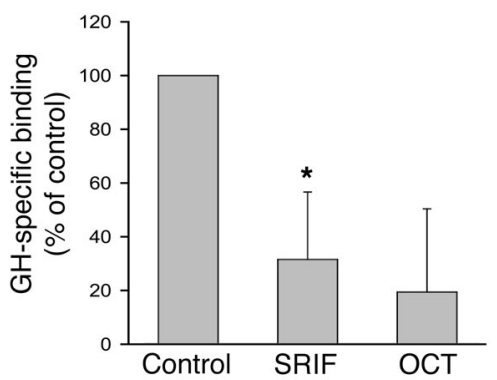

\section{Figure 4}

Primary hepatocytes were incubated with vehicle (Control), SRIF, or OCT for 30 minutes before addition of ${ }^{2} 25 \mathrm{I}-\mathrm{GH}$. Additional wells were treated in the presence of $5 \mu \mathrm{g}$ unlabeled $\mathrm{GH}$ to quantify residual nonspecific binding. Cells were incubated for 30 minutes in the presence of ${ }^{2} 5 \mathrm{I}-\mathrm{GH}$, washed 3 times, and harvested and radioactivity counted. Graph represents total binding with indicated treatment minus nonspecific binding (specific binding). ${ }^{*} P<0.05$ compared with control wells.

tion, hepatocytes were incubated with GH $(500 \mathrm{ng} / \mathrm{ml})$ with or without 100 nM SRIF for 1-30 minutes. Whole-cell lysates were analyzed by Western blot and membranes probed for phosphoextracellular signal regulated kinase (pERK) and, after stripping, re-probed for ERK. As expected, GH increased pERK in a timedependent manner with maximal levels at 5-10 minutes, which returned to baseline by 30 minutes (Figure 5A, lanes 1-6). Coincubation of hepatocytes with GH and SRIF did not alter either the temporal or quantitative effect of GH on ERK phosphorylation (Figure 5A, lanes 7-11). Additional hepatocyte cultures were incubated with GH $(500 \mathrm{ng} / \mathrm{ml})$ in the presence or absence of $100 \mathrm{nM}$ SRIF or octreotide for 30 minutes and RNA analyzed by Northern blot analysis for c-myc. Levels of c-myc were increased by GH; however, coincubation with SRIF or octreotide did not abrogate GHinduced c-myc increase (Figure 5B). SRIF therefore inhibits GHinduced IGF-I, but not GH-induced phosphorylation of ERK or $\mathrm{c}$-myc transcription. Thus, in the hepatocyte, the inhibitory effect of SRIF on GH-stimulated pathways appears specific for IGF-I and does not appear to abrogate pathways independently involved in $\mathrm{GH}$ regulation of cellular growth and differentiation.

SSTR inbibition of IGF-I is inhibitory G-protein-dependent and does not require induction of a protein intermediary. To confirm that the effect of SRIF was transduced by inhibitory G-proteins ( $\mathrm{G}_{i}$ 's) associated with SSTR action, hepatocytes were incubated with pertussis toxin, a specific inhibitor of $\mathrm{G}_{\mathrm{i}}$ 's, for 24 hours before treatment with SRIF or octreotide. As described previously, cells were stimulated with GH $(500 \mathrm{ng} / \mathrm{ml}) 1$ hour after addition of $100 \mathrm{nM}$ SRIF or octreotide, and incubated for a further 24 hours before harvesting cells for RNA. As shown above, GH treatment increased IGF-I mRNA, and this increase was attenuated by SRIF or octreotide. Preincubation with pertussis toxin abrogated the inhibitory effect of SRIF and octreotide on GH-induced IGF-I (Figure 6A), which indicates that SRIF inhibition of GH-induced IGF-I is transduced via $G_{i}$ 's associated with SSTRs.

The two major cellular pathways leading to inactivation of GH signaling following ligand induced GH receptor (GHR) activation are transcription of suppressors of cytokine signaling (SOCS) proteins that bind to and inactivate the GHR-janus kinase-2 (GHR-JAK2) complex; and secondly activation of protein tyrosine phosphatases (PTP) that dephosphorylate tyrosine kinases (GHR and JAK2) and their phosphorylated downstream messengers, the signal transducers and activators of transcription (STATs) $(33,34)$. SOCS proteins require transcription, whereas PTPs are constitutively present and require activation. To determine whether the inhibitory effect of SRIF necessitated translation of a protein, intermediate hepatocytes were treated with $10 \mu \mathrm{g} / \mathrm{ml}$ cycloheximide one and 2 hours before treatment with SRIF and GH respectively, and incubated for 6 hours following GH stimulation. Analysis of IGF-I by RPA revealed a lower fold-induction of IGF-I by GH than observed after 24 hour incubation (Figure 6B, lanes 1-4). Cycloheximide, however, did not abrogate SRIF inhibition of GH-induced IGF-I (Figure 6B, lanes 5-6). Further analysis by real-time PCR measurement of IGF-I showed cycloheximide to have no effect on SRIF or octreotide inhibition of GH-induced IGF-I mRNA (Figure 6C). In keeping with this finding, Northern blots examining SOCS2 and SOCS3 levels in hepatocytes treated with GH alone or in the presence of SRIF showed increased SOCS2 and SOCS3 in the presence of GH that was not further enhanced by coincubation with SRIF (data not shown). These results indicate that SRIF inhibition of $\mathrm{GH}$-induced IGF-I does not require translation of a protein intermediate, such as SOCS, but likely effects its action via activation of pre-established signaling pathways.

SRIF inbibits phosphorylation and nuclear localization of STAT5b. Both $\operatorname{SRIF}(1,35)$ and $\mathrm{GH}(34)$ are reported to increase PTP activity upon binding to their respective receptors. To determine whether PTP may play a role in inhibition of GH signaling by SRIF, hepatocytes were incubated with GH (500 ng/ml), SRIF (100 nM), or a combination of GH and SRIF and harvested after 20 minutes incubation at $37^{\circ} \mathrm{C}$. Although no increase in PTP activity was detected with either ligand alone, the combination of GH and SRIF led to a synergistic increase in PTP activity to $36 \%$ above baseline levels (Figure 7A), which suggests a mechanism by which hepatocyte GH signaling may be prematurely terminated in the presence of SRIF. STAT5b has been implicated as the major pathway by which GH
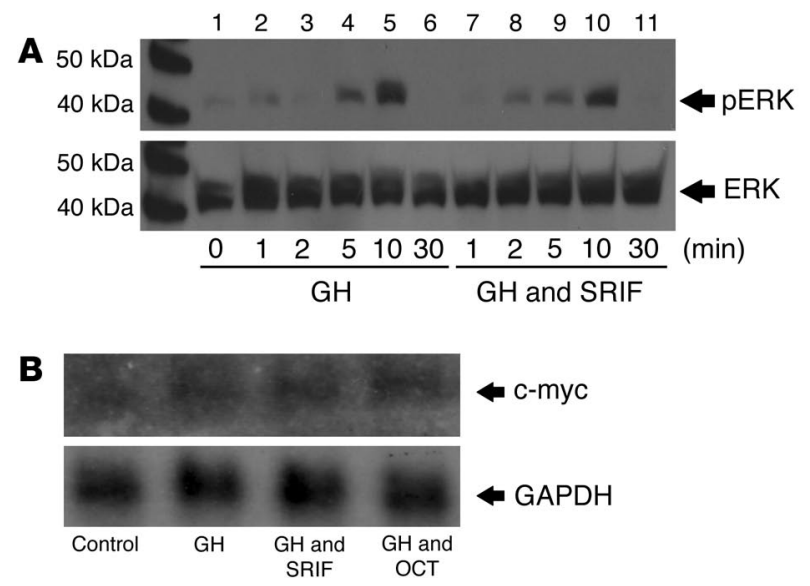

\section{Figure 5}

Hepatocyte GH signaling. (A) Western blot analysis of $50 \mu \mathrm{g}$ protein from primary rat hepatocytes treated with $\mathrm{GH}$ in the absence or presence of SRIF for 1-30 minutes. Membranes were blotted for phosphoERK (pERK; upper panel, $42 \mathrm{kDa}$ ) and ERK (lower panel). (B) Northern blot analysis of RNA from cultured primary hepatocytes treated with vehicle, $\mathrm{GH}$, or $\mathrm{GH}$ in the presence of SRIF or octreotide for 30 minutes. Membranes were probed for c-myc (upper panel), stripped, and reprobed for GAPDH to correct for loading. 
A

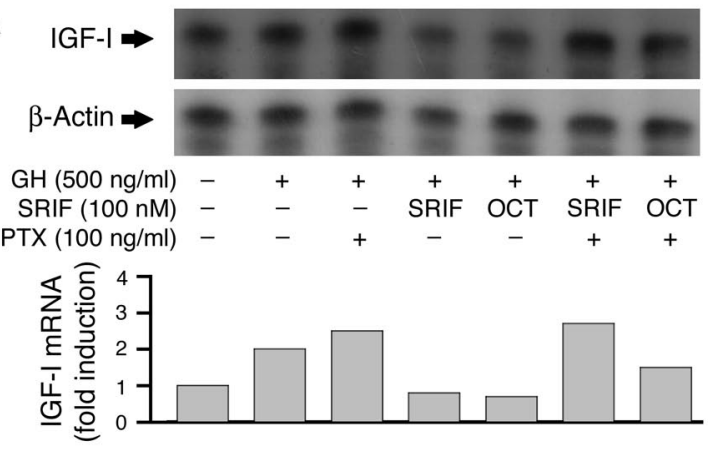

B
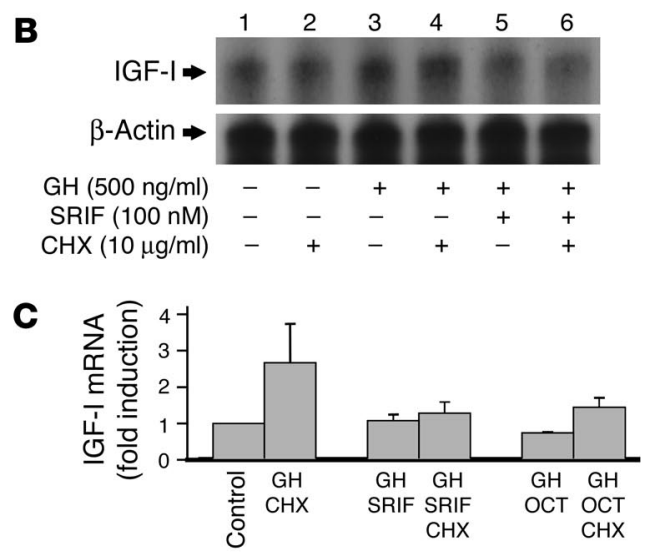

Figure 6

SRIF suppression of hepatic IGF-I does not require new protein induction. (A) Isolated primary hepatocytes were pretreated with vehicle or pertussis toxin (PTX, $100 \mathrm{ng} / \mathrm{ml}$ ) for 24 hours; vehicle, $100 \mathrm{nM}$ SRIF, or octreotide were added; and the cells stimulated with GH (500 ng/ $\mathrm{ml}$ ) one hour later. Cells were incubated for an additional 20 hours and cells harvested. RNA was analyzed for IGF-I content by RPA and loading normalized by $\beta$-actin quantitation. The upper panel shows a representative blot, and the lower panel shows mean fold induction of IGF-I mRNA after normalization for $\beta$-actin. (B) Primary hepatocytes were pretreated with vehicle or cycloheximide $(\mathrm{CHX}, 10 \mu \mathrm{g} / \mathrm{ml})$ for 2 hours and vehicle, $100 \mathrm{nM}$ SRIF, or octreotide for 1 hour before stimulation with $\mathrm{GH}(500 \mathrm{ng} / \mathrm{ml})$. Cells were incubated for an additional 6 hours and harvested. RNA was analyzed for IGF-I content by RPA and loading normalized by quantitation of $\beta$-actin. (C) Primary hepatocytes were treated as for $\mathbf{B}$ and IGF-I RNA content quantitated by real-time $\mathrm{PCR}$ and normalized for $\beta$-actin.

induces IGF-I $(36,37)$. Following GH receptor binding, STAT5b is phosphorylated, dimerizes, and translocates to the nucleus, where it activates transcription $(33,38)$. Hepatocytes, pretreated with SRIF or vehicle for 30 minutes, were stimulated with GH and cells lysed 20 minutes later. STAT5b was immunoprecipitated from whole-cell lysates and subjected to polyacrylamide gel electrophoresis; membranes were probed for phosphotyrosine and, after being stripped, were re-probed for STAT5b. Two distinct STAT5b bands were visualized, the lower at $92 \mathrm{kDa}$ representing tyrosine-phosphorylated STAT5b and the upper band ( $\sim 96 \mathrm{kDa})$ likely representing tyrosinephosphorylated STAT5b that is additionally phosphorylated on serine residues (39) (Figure 7B, upper panel). GH increased both the 92- and 96-kDa phosphorylated STAT5b bands (Figure 7B, upper panel). The GH-induced increase in the $96-\mathrm{kDa}$ band was also clearly visualized when probed for STAT5b (Figure 7B, lower panel). In the presence of SRIF, GH did not induce STAT5b phosphorylation
(Figure 7B, lane 3, upper panel). STAT5b was immunoprecipitated from the nuclear extract of cells treated with $\mathrm{GH}$ or a combination of GH and SRIF for 2-30 minutes. Samples were electrophoresed, and membranes probed for STAT5b. GH increased nuclear STAT5 levels, which peaked at 2-5 minutes. In the presence of SRIF, levels of STAT5 were attenuated (Figure 7C). SRIF, therefore, inhibits both phosphorylation of STAT5b by GH and its subsequent nuclear localization, which provides a mechanism by which SRIF inhibits hepatocyte GH induction of IGF-I.

\section{Discussion}

Acromegaly results from excess GH secretion and, consequently, elevated IGF-I levels (7). Acromegaly features result from excess hormone secretion, local effects of the tumor mass, and hormone deficiencies resulting from compression of normal pituitary tissue (7). SRIF analogs provide the mainstay of medical therapy because of their ability to control hormone secretion in more than $65 \%$ of patients and tumor growth in almost all patients $(19,20,22,23$, $25)$. The mechanism of SRIF analog action in acromegaly is generally accepted to be central inhibition of GHRH release from the arcuate nucleus of the hypothalamus (30) and direct suppression of GH release from the pituitary $(28,29)$. In a subset of patients, clinical use of SRIF analogs has suggested greater lowering of serum IGF-I levels than would be predicted from the concomitant drug-induced GH reduction (27). Conversely, in some patients, octreotide fails to suppress IGF-I despite significant falls in GH levels. There are no in vivo or in vitro reports of direct SRIF action on hepatic IGF-I generation. In vivo studies in hypophysectomized rats suggested an inhibitory action of low but not high octreotide doses on GH-induced IGF-I secretion $(32,40)$. Interpretation of these studies is complicated by concurrent inhibition of other hormones that are known to influence in vivo hepatic IGF-I secretion including insulin and thyroid hormones. Therefore, whether the observed in vivo inhibition of hepatic IGF-I by octreotide was a direct effect or secondary to changes in non-GH hormones or hypothalamic influences was unresolved.

SRIF and octreotide inhibited GH release from cultured rat pituitaries and from $\mathrm{GH}$-secreting adenomas, which confirms the central action of SRIF analogs on pituitary GH release. RT-PCR analysis showed hepatocytes to express SSTR2 and SSTR3 subtypes, which adds credence to the hypothesis of a direct inhibitory effect of SRIF on GH-induced IGF-I production. Using a cultured hepatocyte model to isolate hepatocytes from fluctuations in the hormonal milieu that occur with SRIF analog therapy in vivo, we showed that SRIF and octreotide inhibit GHinduced IGF-I transcription and secretion. Further support for the peripheral action of SRIF analogs on liver IGF-I production was obtained by ex vivo hepatic perfusions, which also demonstrated the ability of octreotide to inhibit GH-induced IGF-I. In the isolated hepatocytes, both ligands were effective throughout the dose range studied $\left(10^{-11}-10^{-7} \mathrm{M}\right)$, which included physiological and pharmacological levels. In contrast to a previous report (32), with octreotide, no loss of effect of either SRIF or octreotide was observed at higher doses. Importantly, inhibition of IGF-I was only observed in the presence of GH, which suggests that the mechanism by which SRIF inhibits IGF-I is related to interactions between SRIF and GH signal transduction pathways. Although SRIF inhibited GH-induced IGF-I, no effect of SRIF was observed on GH-induced c-myc mRNA levels or MAPK phosphorylation, which confirms the specificity of SRIF action for IGF-I. 

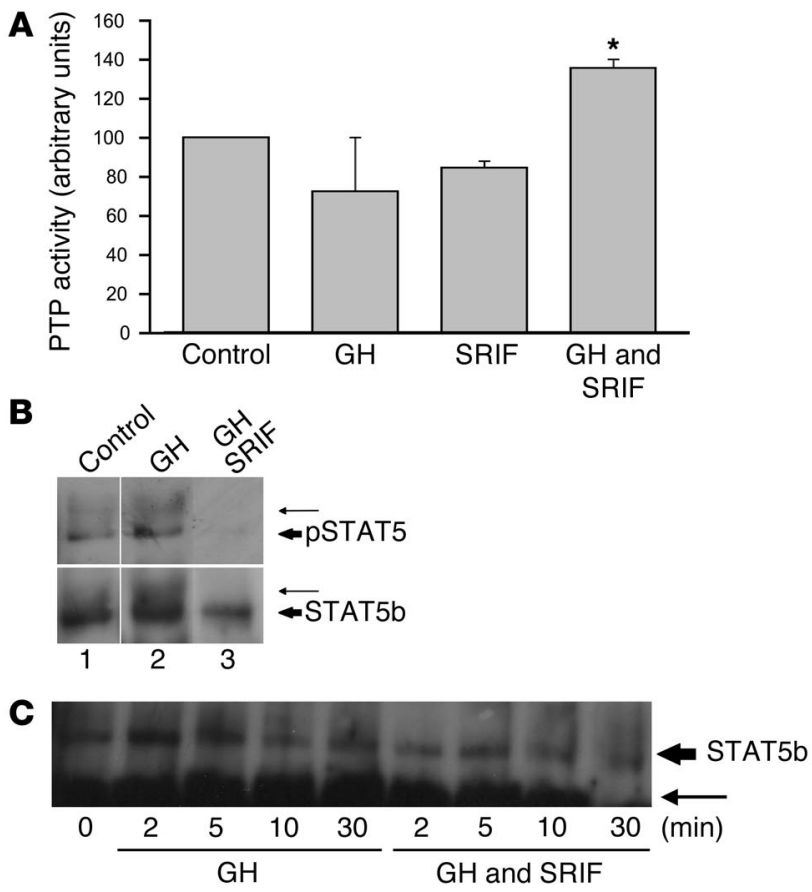

Figure 7

SRIF suppression of STAT5b. (A) PTP activity was measured in primary hepatocytes treated with vehicle (Control), GH (500 ng/ml), and coincubations of GH with 100 nM SRIF or octreotide. PTP activity was assessed by incubation of cell lysates with tyrosine phosphopeptides and the phosphate production measured using a molybdate dye. ${ }^{*} P<0.05$. (B) STAT5b was immunoprecipitated from whole-cell lysates of primary hepatocytes treated with vehicle, $\mathrm{GH}(500 \mathrm{ng} / \mathrm{ml})$, and cotreatments of $\mathrm{GH}$ and $100 \mathrm{nM}$ SRIF for 20 minutes. Immunoprecipitates were subject to polyacrylamide gel electrophoresis and membranes blotted for phospho-STAT5b (upper panel) and, after stripping, for STAT5b (lower panel). Phosphorylated STAT5b (pSTAT5b)/STAT5b was visible as a 92-kDa band; a second band that migrated more slowly was visible at approximately $96 \mathrm{kDa}$ and likely represents serine phosphorylated STAT5b (arrows). (C) STAT5b was immunoprecipitated from hepatocyte nuclear extracts treated with $\mathrm{GH}(500 \mathrm{ng} / \mathrm{ml})$ or cotreated with $\mathrm{GH}$ and $100 \mathrm{nM}$ SRIF. Following electrophoresis, membranes were probed for STAT5b. The lower arrow corresponds to the heavy chain of the IgG used in the immunoprecipitation.

Hepatocyte incubation with cycloheximide to inhibit protein synthesis failed to abrogate inhibitory effects of SRIF or octreotide on GH-induced IGF-I transcription. This observation supports the activation of an established signal transduction regulatory mechanism rather than transcription of a regulatory protein such as SOCS. Coincubation of hepatocytes with SRIF and GH led to synergistic increase in PTP activity and inhibited phosphorylation and nuclear localization of STAT5b. Ligand activation of the GHR leads to GHR dimerization and transphosphorylation of the associated JAK2 kinase residues $(33,38,41)$. In turn, JAK2 kinase phosphorylates STAT5b, which dimerizes and translocates to the nucleus $(33,34$, 42). Phosphorylated STAT5b is proposed to be the primary signal transduction pathway responsible for increased IGF-I transcription following GH stimulation $(36,37)$. It is likely, therefore, that SRIF inhibits GH-induced IGF-I by acting in synergy with GH to enhance PTP activity, which in turn dephosphorylates phospho-STAT5b, leading to premature inactivation of GH signaling. PTPs may act upstream of STAT5 to dephosphorylate JAK2 (43) or the GHR (44), leading to a secondary reduction in STAT5b phosphorylation. Alternatively, PTP may act at several different levels to dephosphorylate GHR, JAK2, and STAT5b. SRIF has been shown to dephosphorylate the epidermal growth factor and platelet-derived growth factor receptors $(45,46)$, members of the cytokine receptor superfamily that includes the GHR, which signal via JAK2 and the STAT proteins. The observation that GH-induced phosphorylation of ERK remained unaffected, while STAT5b was dephosphorylated by coincubation of GH with SRIF, lends support to the selective dephosphorylation of STAT5b, as previously described for SHP-I (34).

In this study, SRIF was also shown to decrease GH binding to hepatocytes. High-dose insulin treatment inhibits GH-induced JAK2 and STAT5 phosphorylation, which similarly was associated with a reduction in GH binding (39). As GH increases membranal expression of its own receptor, it is possible that the phosphorylation state of the GHR-JAK2 complex affects GHR recycling to the membrane. $\mathrm{GH}$ increases phosphorylation of GHR, JAK2, and STAT1, STAT3, and STAT5, which is associated with an increase in membranal GH receptor; whereas SRIF inhibits STAT5 phosphorylation, and possibly phosphorylation of the GHR and JAK2, leading to reduced GH binding to the hepatocyte. Although we observed a significant decrease in GH binding, we did not observe an impact of SRIF or octreotide on non-IGF-I transduction pathways. There are a number of possible explanations for this phenomenon. GH likely stimulates its receptor and activates GHR transduction pathways. The JAK-STAT pathway is abrogated by the concomitant increase in PTPase activity, whereas MAPK is not effected. Decreased GH binding may be a secondary event resulting from decreased GHR recycling. Alternatively, the use of whole cells to estimate GH binding may reflect altered GH internalization rather than binding. Studying isolated hepatocyte cell membranes may resolve the latter alternative.

In summary, the results show that SRIF and its analog, octreotide, inhibit the GH-IGF-I axis both centrally and peripherally at the level of both the pituitary and hepatocyte. In the hepatocyte, SRIF selectively inhibits IGF-I, acting through SSTR2 and 3 and inhibitory G-proteins to increase PTP activity. Increased PTP activity decreases phospho-STAT5b phosphorylation and nuclear localization, leading to premature inactivation of GH signaling and decreased IGF-I transcription. These results provide a mechanistic explanation for understanding SRIF analog action in treating patients with acromegaly.

\section{Methods}

Materials. SRIF-14 and octreotide were purchased from Phoenix Pharmaceuticals (Belmont, California, USA). Human GH was kindly provided by A.F. Parlow of the National Hormone and Peptide Program (Harbor-UCLA Medical Center, Torrance, California, USA). Cell culture media and antibiotics were purchased from Invitrogen Life Technologies (Carlsbad, California, USA). Reagents for ribonuclear protection assays were purchased from Ambion Inc. (Austin, Texas, USA). All other reagents were supplied by SigmaAldrich (St. Louis, Missouri, USA), unless otherwise stated.

Pituitary cell culture. An aliquot from each of six GH-secreting pituitary adenomas obtained at the time of surgery was stored at $-80^{\circ} \mathrm{C}$ for RNA extraction, and the remaining tumor tissue subjected to cell dispersal for culture. Collection and use of human tissue was approved by the Institutional Review Board at Cedars-Sinai Medical Center. Pituitaries were obtained from adult Sprague Dawley rats in accordance with Institutional Animal Care and Use Committee of Cedars-Sinai Medical Center guidelines. Tissue specimens were minced mechanically and enzymatically digested using $0.35 \%$ collagenase $\mathrm{V}$ 
and $0.1 \%$ hyaluronidase for 45 minutes. Cells were suspended in DMEM containing $10 \%$ FCS, centrifuged, and resuspended before seeding in 48-well culture plates at a density of approximately $10^{4}-10^{5} \mathrm{cells} /$ well. Cells were incubated for 48 hours before treatments. Medium was changed to serum-free DMEM with $0.3 \%$ BSA 3 hours before treatments with $10 \mathrm{nM} \mathrm{SRIF,} \mathrm{octreotide,}$ or vehicle in serum-free medium and incubated for an additional 20 hours.

Hepatocyte isolation. In accordance with Institutional Animal Care and Use Committee of Cedars-Sinai Medical Center guidelines, 30- to 45-day-old Sprague Dawley rats were anesthetized and the portal veins exposed and cannulated. The liver was perfused with liver perfusion buffer (Invitrogen Life Technologies), followed by HBSS (Sigma-Aldrich) containing $0.05 \%$ collagenase type IV (Sigma-Aldrich). The capsule of the digested liver was removed and cells dispersed in low-glucose DMEM with 10\% FCS. The hepatocyte suspension was filtered and washed with low-glucose DMEM containing $10 \%$ FCS. For RNA and protein extraction, cells were plated at a density of $10 \times 10^{6}$ to $12 \times 10^{6}$ cells per $10-\mathrm{cm}$ culture dish. For binding studies and IGF-I protein determination, cells were plated at a density of $2.5 \times 10^{5}$ per well in 48-well culture plates. All culture dishes were coated with Matrigel basement matrix (BD, Bedford, Massachusetts, USA) before hepatocyte seeding. After cells were allowed to attach, the medium was changed to Williams E containing $0.25 \% \mathrm{BSA}, 10 \mathrm{mg} / \mathrm{l}$ insulin, $5.5 \mathrm{mg} / \mathrm{l}$ transferrin, $6.7 \mathrm{mg} / \mathrm{l}$ selenium, $50,000 \mathrm{U} / \mathrm{l}$ penicillin, and $50 \mathrm{mg} / \mathrm{l}$ streptomycin and incubated for an additional 40 hours before treatments. Treatments were administered in the supplemented Williams medium described above as specified for each study. Control treatments consisted of the appropriate drug vehicle.

Rat liver perfusions. Thirty- to 45-day-old Sprague Dawley rats were anesthetized and the portal vein exposed and cannulated. The liver was removed in totality and perfused ex vivo with Krebs buffer at $12 \mathrm{ml} / \mathrm{min}$ according to one of the following protocols: (a) buffer for 60 minutes; (b) sequentially with buffer for 15 minutes, $\mathrm{GH}(500 \mathrm{ng} / \mathrm{ml})$ for 10 minutes, and buffer for 35 minutes; (c) sequentially with octreotide $(20 \mathrm{ng} / \mathrm{g}$ body $\mathrm{wt} / \mathrm{h})$ for 15 minutes, $\mathrm{GH}(500 \mathrm{ng} / \mathrm{ml})$ plus octreotide for 10 minutes, and octreotide for 35 minutes. Immediately following the perfusion, an aliquot of the liver was lysed for analysis of IGF-I protein content.

Assays. Rat GH was measured by RIA after appropriate sample dilution using reagents kindly provided by A.F. Parlow. Human GH was measured using an RIA kit (Diagnostic Products Corporation, Los Angeles, California, USA). IGF-I was measured by RIA after acid-alcohol extraction using a kit specific for rat IGF-I (Diagnostic System Laboratories, Webster, Texas, USA). PTP activity was measured in cell lysates using the Tyrosine Phosphatase Assay System (Promega, Madison, Wisconsin, USA). In brief, cell lysates were centrifuged at $100,000 \mathrm{~g}$ for one hour and endogenous phosphate removed from the supernatant by passing through Sephadex G25 columns (Promega, Madison, Wisconsin, USA). Thirty-five microliters of each sample was incubated with tyrosine phosphopeptides for 45 minutes in $60 \mathrm{mM} \mathrm{Na}$ acetate ( $\mathrm{pH}$ 5.2) and the reaction terminated by addition of a molybdate dye. Optical density was read at $630 \mathrm{~nm}$ and PTP activity normalized for protein concentration of the lysates.

RT-PCR analysis. RNA was extracted from isolated rat hepatocytes using TRIzol reagent (Invitrogen Life Technologies). In brief, tissue was homogenized in TRIzol and subject to chloroform phase separation. RNA was precipitated from the aqueous phase by isopropanol, collected by centrifugation, washed with $70 \%$ ethanol $/ 30 \%$ diethyl-pyrocarbonate (DEPC) water and resuspended in DEPC water at a concentration of 1-3 $\mu \mathrm{g} / \mu \mathrm{l}$. Three micrograms RNA was incubated with RNase-free deoxyribonuclease-I (Roche Diagnostics, Mannheim, Germany) to eliminate contaminating genomic DNA. For synthesis of first-strand cDNA, RNA was reverse transcribed by incubation with Oligo(dT) primers and Omniscript reverse transcriptase (RT+) (Qiagen, Valencia, California, USA). A negative control was performed by running the reaction in the absence of reverse transcriptase enzyme (RT-). Fidelity of the RT reaction was assessed by PCR using primers for GAPDH (Table 1). Thirty-five-cycle PCR reactions for each of the five SSTR subtypes were performed using Platinum Taq DNA polymerase (Invitrogen Life Technologies) and primers specific for the rat SSTR subtypes (Table 1). Identical negative control reactions were performed on the RT-sample. Positive control reactions were performed using plasmids containing the appropriate full-length SSTR as a template.

$R P A$. Because of the presence of multiple IGF-I transcripts (47), primers corresponding to the IGF-I protein, and therefore common to all IGF-I transcripts, were used to obtain a specific 166-base-pair cDNA sequence from rat hepatocyte cDNA by PCR. The PCR product obtained was subcloned into a plasmid (PCRII-TOPO; Invitrogen Life Technologies) containing both the SP6 and T7 RNA polymerase promoters. Chemically competent Escherichia coli were transformed with the plasmid, individual colonies amplified, and the plasmid extracted (QIAprep Miniprep kit; Qiagen) and sequenced (ABI PRISM BigDye Terminator v3.0 Cycle Sequencing Ready Reaction Kit; Applied Biosystems, Foster City, California, USA) to confirm precision and orientation of the insert. The plasmid was linearized with $\mathrm{XbaI}$ and the riboprobe transcribed by incubation for one hour at $37^{\circ} \mathrm{C}$ with ${ }^{32} \mathrm{P}-\mathrm{UTP}$ and SP6 RNA polymerase (MAXIscript; Ambion Inc.). Twenty micrograms of sample RNA was incubated with $5 \times 10^{5} \mathrm{cpm}$ of IGF-I riboprobe and a commercially available $\beta$-actin riboprobe (pTRI- $\beta$-actin-125-Rat; Ambion Inc.) at $52^{\circ} \mathrm{C}$ overnight in hybridization buffer according to the manufacturer's protocol (RPA III; Ambion Inc.). The hybridized RNA was digested with RNase A/T1 mix, precipitated, resuspended in loading buffer, and run on an $8 \%$ acrylamide $/ 8 \mathrm{M}$ urea denaturing gel.

Relative gene expression analysis by real-time PCR. PCR reactions containing 400 ng template cDNA, $400 \mathrm{nM}$ each forward and reverse primer, and $1 \mathrm{X}$ SYBR Green in $25 \mu \mathrm{l}$ were amplified for 50 cycles in a Bio-Rad iCycler (Bio-Rad Laboratories, Hercules, California, USA) with an initial melt temperature at $95^{\circ} \mathrm{C}$ for 15 minutes followed by 50 cycles of $95^{\circ} \mathrm{C}$ for 15 seconds, $58^{\circ} \mathrm{C}$ for $20 \mathrm{sec}$ onds, and $72^{\circ} \mathrm{C}$ for 30 seconds. PCR product accumulation was monitored during each cycle by measuring increased fluorescence caused by intercalation of SYBR Green (Molecular Probes, Eugene, Oregon, USA) with double-stranded DN (dsDNA). The cycle at which a significant increase in PCR product was detected (threshold cycle) was used to quantitate relative amounts of starting product in each sample. A passive reference dye, fluorescein, was used to normalize for variations in volume and dye concentrations between wells. Postamplification melting curves were used to confirm that a single PCR product was produced. The PCR product of each sample was normalized for $\beta$-actin. The contribution of contaminating genomic DNA was less than $0.1 \%$.

Northern blot analysis. Total RNA extracted from hepatocytes was electrophoresed on agarose/formaldehyde gels and transferred to Hybond $\mathrm{N}$ nylon membranes (Amersham Pharmacia, Buckinghamshire, UK). Membranes were prehybridized with Quik-Hyb hybridization buffer (Stratagene, La Jolla, California, USA) for 6 hours and probed overnight at $68^{\circ} \mathrm{C}$ with ${ }^{32} \mathrm{P}$-dCTP-labeled probes for c-myc, SOCS2, or SOCS3. Membranes were stripped and rehybridized for GAPDH to correct for RNA loading.

Western blot analysis. Protein samples prepared in RIPA buffer were resolved under reducing conditions on 10-20\% SDS-polyacrylamide gels. Nuclear protein extract was prepared according to the manufacturer's protocol using the CellLytic NuCLEAR extraction kit (Sigma-Aldrich). STAT5b immunoprecipitation was performed by incubating $500 \mu \mathrm{g}$ whole-cell extract or $300 \mu \mathrm{g}$ nuclear extract with $0.5 \mu \mathrm{g}$ anti-STAT5b (BD Biosciences - Pharmingen, San Diego, California, USA) overnight at $4^{\circ} \mathrm{C}$. Following further incubation of the STAT5b-antibody complex with $40 \mu$ protein-A agarose for 2 hours, samples were washed and electrophoresed. Resolved proteins were transferred to nitrocellulose membranes and probed with antibodies against phospho-ERK (1:500) and ERK (1:2,000), pTyr (1:500), or STAT5b (1:500; Santa Cruz Biotechnology, California, USA). After washing, 
membranes were probed with appropriate IgG-HRP conjugates and visualized with ECL Western blotting detection kit (Amersham Pharmacia).

${ }^{125} \mathrm{I}$-GH binding assay. Hepatocytes were treated with SRIF, octreotide, or vehicle for 30 minutes before incubation with approximately $10^{5} \mathrm{cpm}$ ${ }^{125} \mathrm{I}$-GH with or without $5 \mu \mathrm{g}$ unlabeled $\mathrm{GH}$ at $37^{\circ} \mathrm{C}$ for 30 minutes. Following incubation, cells were washed three times in $4^{\circ} \mathrm{C}$ PBS, harvested with trypsin, and counted in a $\gamma$-counter.

Statistical analysis. Data are presented as mean \pm SD in the text, and as mean \pm SEM when represented graphically. Differences between data sets were examined using ANOVA on ranks or ANOVA for nonparametric and parametric data respectively. Nonpaired data were compared using the Mann-Whitney rank sum test and Student's $t$ test. A $P$ value of $<0.05$ was deemed significant.

\section{Acknowledgments}

This work is supported by grants from the NIH (CA 75979), Novartis Pharmaceuticals, and the Doris Factor Molecular Endocrinology Laboratory.

Received for publication September 2, 2003, and accepted in revised form June 8, 2004.

Address correspondence to: Shlomo Melmed, Academic Affairs, Room 2015, Cedars Sinai Medical Center, 8700 Beverly Boulevard, Los Angeles, California 90048, USA. Phone: (310) 423-4691; Fax: (310) 423-0119; E-mail: melmed@csmc.edu.
1. Schonbrunn, A. 1999. Somatostatin receptors present knowledge and future directions [review]. Ann. Oncol. 10(Suppl. 2):S17-S21.

2. Hofland, L.J., and Lamberts, S.W. 2003. The pathophysiological consequences of somatostatin receptor internalization and resistance. Endocr. Rev. 24:28-47.

3. Udy, G.B., et al. 1997. Requirement of STAT5b for sexual dimorphism of body growth rates and liver gene expression. Proc. Natl. Acad. Sci. U. S. A. 94:7239-7244.

4. Sjogren, K., et al. 1999. Liver-derived insulin-like growth factor I (IGF-I) is the principal source of IGF-I in blood but is not required for postnatal body growth in mice. Proc. Natl. Acad. Sci. U. S. A. 96:7088-7092.

5. Yakar, S., et al. 1999. Normal growth and development in the absence of hepatic insulin-like growth factor I. Proc. Natl. Acad. Sci. U. S. A. 96:7324-7329.

6. Le Roith, D., Bondy, C., Yakar, S., Liu, J.L., and Butler, A. 2001. The somatomedin hypothesis: 2001. Endocr. Rev. 22:53-74.

7. Melmed, S. 1990. Acromegaly. N. Engl. J. Med. 322:966-977.

8. Bates, A.S., Van't Hoff, W., Jones, J.M., and Clayton, R.N. 1993. An audit of outcome of treatment in acromegaly. Q. J. Med. 86:293-299.

9. Bengtsson, B.A., Eden, S., Ernest, I., Oden, A., and Sjogren, B. 1988. Epidemiology and long-term survival in acromegaly. A study of 166 cases diagnosed between 1955 and 1984. Acta Med. Scand. 223:327-335.

10. Alexander, L., Appleton, D., Hall, R., Ross, W.M., and Wilkinson, R. 1980. Epidemiology of acromegaly in the Newcastle region. Clin. Endocrinol. (Oxf.). 12:71-79.

11. Swearingen, B., et al. 1998. Long-term mortality after transsphenoidal surgery and adjunctive therapy for acromegaly. J. Clin. Endocrinol. Metab. 83:3419-3426.

12. Renehan, A.G., et al. 2000. The prevalence and characteristics of colorectal neoplasia in acromegaly. J. Clin. Endocrinol. Metab. 85:3417-3424.

13. Biermasz, N.R., van Dulken, H., and Roelfsema, F. 2000. Ten-year follow-up results of transsphenoidal microsurgery in acromegaly. J. Clin. Endocrinol. Metab. 85:4596-4602.

14. Kreutzer, J., Vance, M.L., Lopes, M.B., and Laws, E.R., Jr. 2001. Surgical management of GH-secreting pituitary adenomas: an outcome study using modern remission criteria. J. Clin. Endocrinol. Metab. 86:4072-4077.

15. Biermasz, N.R., Dulken, H.V., and Roelfsema, F. 2000 Postoperative radiotherapy in acromegaly is effective in reducing $\mathrm{GH}$ concentration to safe levels. Clin. Endocrinol. (Oxf.). 53:321-327.

16. Abs, R., et al. 1998. Cabergoline in the treatment of acromegaly: a study in 64 patients. J. Clin. Endocrinol. Metab. 83:374-378.

17. Melmed, S., et al. 2002. Guidelines for acromegaly management. J. Clin. Endocrinol. Metab. 87:4054-4058.

18. Kleinberg, D.L., et al. 1983. Pergolide for the treatment of pituitary tumors secreting prolactin or growth hormone. N. Engl. J. Med. 309:704-709.

19. Colao, A., et al. 2001. Long-term effects of depot long-acting somatostatin analog octreotide on hormone levels and tumor mass in acromegaly. J. Clin. Endocrinol. Metab. 86:2779-2786.

20. Newman, C.B., et al. 1998. Octreotide as primary therapy for acromegaly. J. Clin. Endocrinol. Metab. 83:3034-3040.

21. Bevan, J.S., et al. 2002. Primary medical therapy for acromegaly: an open, prospective, multicenter study of the effects of subcutaneous and intramuscular slow-release octreotide on growth hormone, insulin-like growth factor-I, and tumor size. J. Clin. Endocrinol. Metab. 87:4554-4563.

22. Ayuk, J., Stewart, S.E., Stewart, P.M., and Sheppard, M.C. 2002. Long-term safety and efficacy of depot long-acting somatostatin analogs for the treatment of acromegaly. J. Clin. Endocrinol. Metab. 87:4142-4146.

23. Ezzat, S., et al. 1992. Octreotide treatment of acromegaly. A randomized, multicenter study. Ann. Intern. Med. 117:711-718.

24. Lamberts, S.W., Uitterlinden, P., Verschoor, L., van Dongen, K.J., and del Pozo, E. 1985. Long-term treatment of acromegaly with the somatostatin analogue SMS 201-995. N. Engl. J. Med. 313:1576-1580.

25. Vance, M.L., and Harris, A.G. 1991. Long-term treatment of 189 acromegalic patients with the somatostatin analog octreotide. Results of the International Multicenter Acromegaly Study Group. Arch. Intern. Med. 151:1573-1578.

26. Turner, H.E., Vadivale, A., Keenan, J., and Wass, J.A. 1999. A comparison of lanreotide and octreotide LAR for treatment of acromegaly. Clin. Endocrinol. (Oxf.). 51:275-280.

27. Quabbe, H.J., and Plockinger, U. 1989. Dose-response study and long term effect of the somatostatin ana$\log$ octreotide in patients with therapy-resistant acromegaly. J. Clin. Endocrinol. Metab. 68:873-881.

28. Shimon, I., et al. 1997. Somatostatin receptor subtype specificity in human fetal pituitary cultures. Differential role of SSTR2 and SSTR5 for growth hormone, thyroid-stimulating hormone, and prolactin regulation. J. Clin. Invest. 99:789-798.

29. Shimon, I., et al. 1997. Somatostatin receptor (SSTR) subtype-selective analogues differentially suppress in vitro growth hormone and prolactin in human pituitary adenomas. Novel potential therapy for functional pituitary tumors. J. Clin. Invest. 100:2386-2392.

30. Zheng, H., et al. 1997. Somatostatin receptor subtype 2 knockout mice are refractory to growth hormone-negative feedback on arcuate neurons. $\mathrm{Mol}$. Endocrinol. 11:1709-1717.

31. Bruno, J.F., Xu, Y., Song, J., and Berelowitz, M. 1993. Tissue distribution of somatostatin receptor subtype messenger ribonucleic acid in the rat. Endocrinology. 133:2561-2567.

32. Serri, O., Brazeau, P., Kachra, Z., and Posner, B. 1992. Octreotide inhibits insulin-like growth factor-I hepatic gene expression in the hypophysectomized rat: evidence for a direct and indirect mechanism of action. Endocrinology. 130:1816-1821.
33. Argetsinger, L.S., and Carter-Su, C. 1996. Mechanism of signaling by growth hormone receptor. Physiol. Rev. 76:1089-1107.

34. Ram, P.A., and Waxman, D.J. 1997. Interaction of growth hormone-activated STATs with SH2-containing phosphotyrosine phosphatase SHP-1 and nuclear JAK2 tyrosine kinase. J. Biol. Chem. 272:17694-17702.

35. Pan, M.G., Florio, T., and Stork, P.J. 1992. G protein activation of a hormone-stimulated phosphatase in human tumor cells. Science. 256:1215-1217.

36. Woelfle, J., Billiard, J., and Rotwein, P. 2003. Acute control of insulin-like growth factor-I gene transcription by growth hormone through Stat $5 \mathrm{~b}$. J. Biol. Chem. 278:22696-22702.

37. Davey, H.W., et al. 2001. STAT5b is required for $\mathrm{GH}$-induced liver IGF-I gene expression. Endocrinology. 142:3836-3841.

38. Postel-Vinay, M.C., and Kelly, P.A. 1996. Growth hormone receptor signalling. Baillieres Clin. Endocrinol. Metab. 10:323-336.

39. Ji, S., Guan, R., Frank, S.J., and Messina, J.L. 1999. Insulin inhibits growth hormone signaling via the growth hormone receptor/JAK2/STAT5B pathway. J. Biol. Chem. 274:13434-13442.

40. Flyvbjerg, A., Jorgensen, K.D., Marshall, S.M., and Orskov, H. 1991. Inhibitory effect of octreotide on growth hormone-induced IGF-I generation and organ growth in hypophysectomized rats. Am.J. Physiol. 260:E568-E574.

41. Wang, X., Darus, C.J., Xu, B.C., and Kopchick, J.J. 1996. Identification of growth hormone receptor (GHR) tyrosine residues required for GHR phosphorylation and JAK2 and STAT5 activation. Mol. Endocrinol. 10:1249-1260.

42. Moulin, S., Bouzinba-Segard, H., Kelly, P.A., and Finidori, J. 2003. Subcellular Trafficking of Growth Hormone Receptor and Jak2 under Ligand Exposure. Horm. Metab. Res. 35:396-401.

43. Gu, F., et al. 2003. Protein tyrosine phosphatase 1B attenuates growth hormone-mediated JAK2-STAT signaling. Mol. Cell. Biol. 23:3753-3762.

44. Pasquali, C., et al. 2003. Identification of Protein Tyrosine Phosphatases with specificity for the ligand-activated GH Receptor. Mol. Endocrinol. 17:2228-2239.

45. Held-Feindt, J., Forstreuter, F., Pufe, T., and Mentlein, R. 2001. Influence of the somatostatin receptor sst 2 on growth factor signal cascades in human glioma cells. Brain Res. Mol. Brain Res. 87:12-21.

46. Lee, M.T., Liebow, C., Kamer, A.R., and Schally, A.V. 1991. Effects of epidermal growth factor and analogues of luteinizing hormone-releasing hormone and somatostatin on phosphorylation and dephosphorylation of tyrosine residues of specific protein substrates in various tumors. Proc. Natl. Acad. Sci. U. S. A. 88:1656-1660.

47. Lowe, W.L., Jr., Roberts, C.T., Jr., Lasky, S.R., and LeRoith, D. 1987. Differential expression of alternative 5 ' untranslated regions in mRNAs encoding rat insulin-like growth factor I. Proc. Natl. Acad. Sci. U. S. A. 84:8946-8950. 